Relations industrielles

Industrial Relations

\title{
Years of Hard Labour, par Morden Lazarus, Don Mills, Ontario Federation of Labour, 1974, 115 pp.
}

\section{Gérard Dion}

Volume 30, numéro 2, 1975

URI : https://id.erudit.org/iderudit/028613ar

DOI : https://doi.org/10.7202/028613ar

Aller au sommaire du numéro

Éditeur(s)

Département des relations industrielles de l'Université Laval

ISSN

0034-379X (imprimé)

1703-8138 (numérique)

Découvrir la revue

Citer ce compte rendu

Dion, G. (1975). Compte rendu de [Years of Hard Labour, par Morden Lazarus, Don Mills, Ontario Federation of Labour, 1974, 115 pp.] Relations industrielles / Industrial Relations, 30(2), 271-271. https://doi.org/10.7202/028613ar

Tous droits réservés (C) Département des relations industrielles de l'Université Laval, 1975
Ce document est protégé par la loi sur le droit d'auteur. L’utilisation des services d'Érudit (y compris la reproduction) est assujettie à sa politique d'utilisation que vous pouvez consulter en ligne.

https://apropos.erudit.org/fr/usagers/politique-dutilisation/ 


\section{RECENSIONS BOOK REVIEWS}

Strike : A Live History, 1887-1971, by R.A. Leeson, London, George Allen \& Unwin Ltd., 1973, 246 pp.

Ce livre présente un caractère assez inusité car il raconte les témoignages de quelque 85 personnes ayant participé activement à environ 150 conflits de travail survenus en Grande-Bretagne entre 1887 et 1971 . La plupart des événements sont racontés directement par les personnes les ayant vécus et l'auteur leur laisse la parole tout au long du volume.

Les débuts du livre remontent aussi loin qu'à l'époque de la reine Victoria et du Premier ministre Gladstone. Les premiers conflits commentés sont ceux des travailleurs de la jute (dont certains étaient âgés de 10 ans) à Dundee en 1887 et les mineurs de South Wales en 1904. On retrouve ensuite des commentaires intéressants sur des conflits célèbres comme la grève générale de 1926 qui avait été déclenchée par la très fragile triple alliance entre les mineurs, les débardeurs et les cheminots et dont l'échec culmina dans le nom moins célèbre «Vendredi noir».

Le livre contient également une série d'illustrations montrant diverses scènes où les grévistes sont rassemblés de même que des caricatures et des articles de journaux.

Le choix des conflits est très judicieux car il permet de reconstituer à toutes fins pratiques l'histoire du syndicalisme britannique et des facteurs socio-politiques ayant influencé son développement. Il est préférable, cependant, de posséder une connaissance préalable des grandes étapes de ce développement, car la lecture des nombreux témoignages risque d'être fastidieuse.

Strike: A Live History, 1887-1971 constitue un excellent complément aux différents livres qui ont déjà été écrits sur l'histoire du syndicalisme britanni- que par Pelling, Morton et Tate et les autres.

\section{Université Laval}

Jean BOIVIN

Years of Hard Labour, par Morden Lazarus, Don Mills, Ontario Federation of Labour, 1974, 115 pp.

Cet ouvrage porte en sous titre «un exposé sur le travailleur canadien, ses organisations et ses tribulations pendant une période de plus de cent ans ». L'auteur, aujourd'hui à la retraite, est un journaliste qui a consacré sa carrière au service du mouvement syndical. Dès le départ, il ne cache pas son préjugé favorable au syndicalisme.

C'est pour combler un vide souvent déploré qu'il a été amené à écrire cette brève histoire du syndicalisme au $\mathrm{Ca}$ nada accessible aux travailleurs et aux étudiants des écoles.

Il n'a pas cherché à tout raconter. En treize chapitres, il s'est limité à retracer sobrement les principaux faits saiillants qui ont marqué le développement des organisations syndicales et des luttes qui ont été menées. Il couvre assez bien la scène canadienne dans son ensemble. Mais, ayant oeuvré en Ontario, il n'est pas surprenant qu'il ait été amené à laisser plutôt dans l'ombre ce qui avait un caractère régional dans les autres provinces. Malgré les recherches qu'il a effectuées et son souci d'exactitude, on regrette que certaines erreurs se soient glissées à divers endroits. Soulignons que le C.P. 1003 n'a pas été édicté en 1943, mais bien en février 1944. Le lecteur appréciera la quinzaine de courtes notices biographiques qu'il a consacrées à des dirigeants qui ont joué un rôle important dans le synlicalisme.

Sans aucune prétention scientifique, c'est un ouvrage honnête, utile, qui répond bien à l'objectif que s'était fixé l'auteur.

Université Laval
Gérard DION 